\title{
MORPHOLOGICAL PECULIARITIES OF THE TESTES IN 41-50-YEARS-OLD MEN
}

\author{
Kristina Lasiené, Donatas Gasiliūnas',

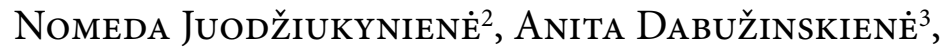 \\ Aleksandras VitKus, Biruté ŽIllaitienE ${ }^{4}$ \\ Department of Histology and Embryology, \\ Lithuanian University of Health Sciences, Kaunas, Lithuania \\ ${ }^{1}$ Kaunas Division of State Forensic Medicine Service, Kaunas, Lithuania \\ ${ }^{2}$ Department of Veterinary Pathobiology, \\ Lithuanian University of Health Sciences, Kaunas Lithuania \\ ${ }^{3}$ Institute of Anatomy, Lithuanian University of Health Sciences, Kaunas, \\ Lithuania \\ ${ }^{4}$ Institute of Endocrinology, Lithuanian University of Health Sciences, Kaunas, \\ Lithuania
}

\begin{abstract}
The morphological parameters such as the length, width, height and weight of 20 pairs of testes were measured in this study. The volume of the testis was calculated using the formula: Volume $=$ length $(\mathrm{L}) \times$ width $(\mathrm{W}) \times$ height $(\mathrm{H})$ $\times 0.71$. These morphological parameters of the right and left testes were compared.

The total length, width and height of both testes of 41-50-years-old men were $4.53 \pm 0.46 \mathrm{~cm}, 3.05 \pm 0.31 \mathrm{~cm}$ and $2.58 \pm 0.36 \mathrm{~cm}$ respectively. The total volume and weight were $25.53 \pm 6.06 \mathrm{~cm}^{3}$ and $20.93 \pm 4.75 \mathrm{~g}$ respectively. The length, height, volume and weight of the right testis were significantly larger than of the left testes in 41-50-years-old men. Only the width of the right and the left testes differed statistically non-significantly.
\end{abstract}

Keywords: men; morphological; testis; volume; weight 


\section{INTRODUCTION}

The testicular morphological parameters have been studied in recent years. The methods used for testicular volume assessment involve the use of callipers, orchidometry or ultrasonography. Orchidometry is a conventional method that has been used for many years. However, the ultrasound measurement of testicular volume is more reliable that orchidometry for patients $[5,10]$. The most rigorous method for measuring of the volume of testis is the Archimedes principle of water displacement $[1,7,9]$. However, this method can be used only for dead patients or after orchiectomy. For live patients, scientists have established some formulas for determining of testicular volume $[3,6,8,9]$.

In adult males, testicular volume and weight are measured in relation to spermatogenic activity. Scientists have ascertained that the left testis is smaller than the right one $[2,4]$.

The aim of this study was to measure and compare the morphological parameters (length, width, height, volume and weight) of 41-50-years-old men's testes.

\section{MATERIAL AND METHODS}

The study was approved by the Kaunas Region Biomedical Research Ethics Committee (No. BE-2-1, 07.04.2015).

The pairs of testes from 20 men aged 41-50 years were obtained from the Kaunas Division of State Forensic Medicine Service after autopsy in 10\% formaldehyde solution. Only testes without visible morphological pathologies were selected as suitable for this investigation. The testes were rinsed in streaming tap water and dried with blotting paper and weighed. The length, width and height of each testis were measured using sliding callipers. The volume of the testis was calculated using the formula: Volume $=$ length $(\mathrm{L}) \times$ width $(\mathrm{W})$ $\times$ height $(\mathrm{H}) \times 0.71[8,9]$.

The Statistica program (Statistica Version 5, StatSoft inc.) was used for statistical analysis of results. The data were expressed as mean \pm standard deviation (SD), and $\mathrm{p}<0.05$ was taken as significant. 


\section{RESULTS}

The total length of both testes of $41-50$-years-old men was $4.53 \pm 0.46 \mathrm{~cm}$. The length of right testes differed significantly from the left $(4.63 \pm 0.46 \mathrm{~cm}$ and $4.44 \pm 0.45 \mathrm{~cm}$ respectively, $\mathrm{p}<0.05$ ) (Figure 1 ).

The total width of men's both testes was $3.05 \pm 0.31 \mathrm{~cm}$. The width of the right testes was larger $(3.08 \pm 0.32 \mathrm{~cm})$ than of the left $(3.02 \pm 0.31 \mathrm{~cm})$, but the difference was statistically non-significant $(\mathrm{p}>0.05)$ (Figure 2$)$.

The total height of both testes in 41-50-years-old men was $2.58 \pm 0.36 \mathrm{~cm}$ (Figure 3$)$. The right testes were significantly higher than the left $(2.68 \pm 0.39 \mathrm{~cm}$ and $2.48 \pm 0.31 \mathrm{~cm}$ respectively, $\mathrm{p}<0.05)$.

Figure 4 shows that the total volume of the right and left testes in 41-50-years-old men was $25.53 \pm 6.06 \mathrm{~cm}^{3}$. The right testes had larger volume than the left $\left(27.31 \pm 6.44 \mathrm{~cm}^{3}\right.$ and $23.75 \pm 5.23 \mathrm{~cm}^{3}$ respectively, $\left.\mathrm{p}<0.05\right)$.

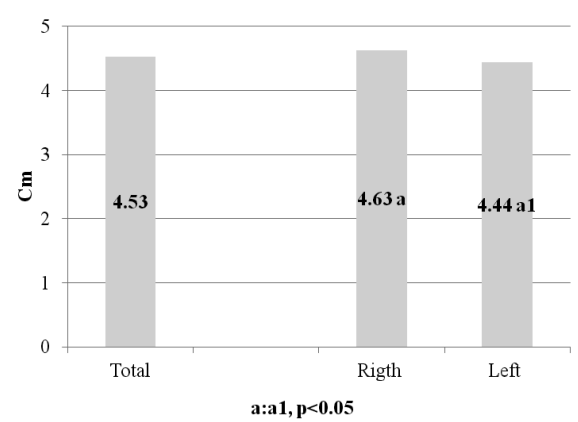

Figure 1. The length of the testes in 41-50-years-old men.

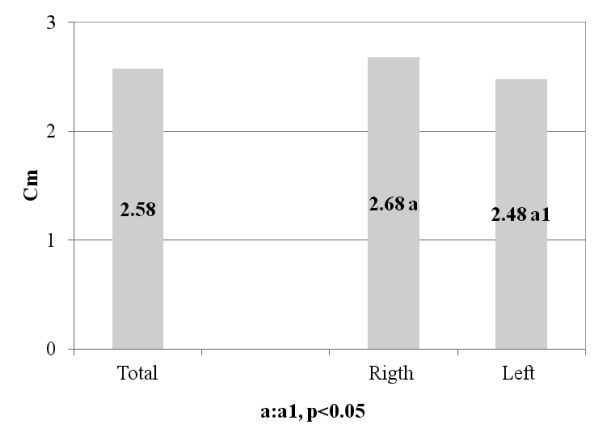

Figure 3. The height of the testes in 41-50-years-old men.

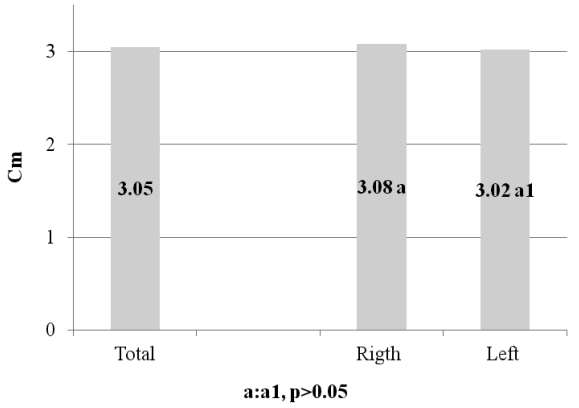

Figure 2. The width of the testes in 41-50-years-old men.

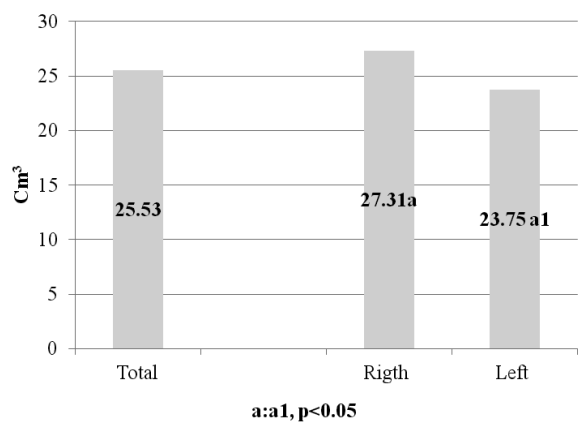

Figure 4. The volume of the testes in 41-50-years-old men. 


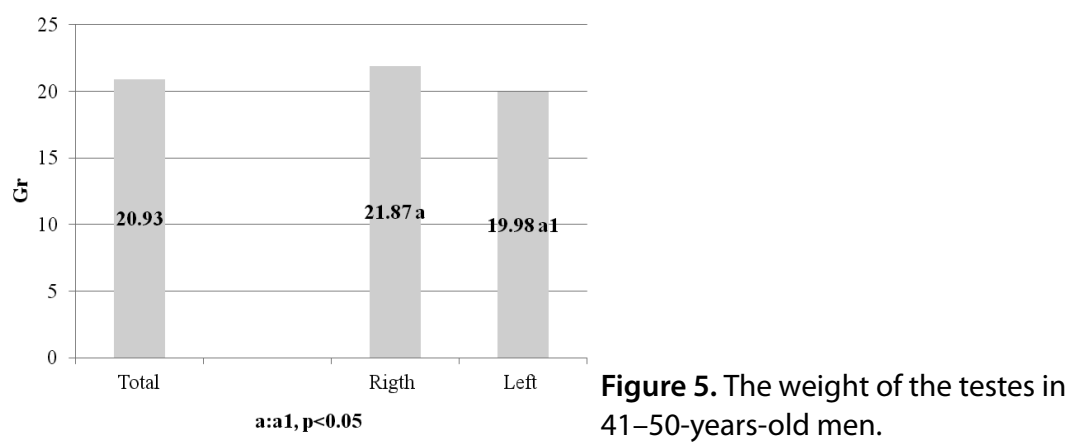

The weight of both testes was $20.93 \pm 4.75 \mathrm{~g}$. The weight of the right and the left testes differed statistically significantly $(21.87 \pm 4.98 \mathrm{~g}$ and $19.98 \pm 4.44 \mathrm{~g}$ respectively, $\mathrm{p}<0.05$, Figure 5).

\section{DISCUSSION}

The peculiarities and differences of human testicular volume have been studied in recent years. Scientists have offered various formulas for determining the testicular volume: (a) for a prolate ellipsoid: volume $=$ length $\times$ width $\times$ height $\times 0.52$; (b) for a prolate spheroid: volume $=$ length $\times$ width $^{2} \times 0.52$; (c) the empiric formula of Lambert: volume $=$ length $\times$ width $\times$ height $\times 0.71$, and (d) volume $=$ length $\times$ width $\times$ height $\times(\pi / 6)$, and others $[3,6,8,9,11]$. Mbaeri with co-authors [8] determined that the most rigorous method for calculating of testis volume is the empiric formula of Lambert. Therefore, we used this formula in our study.

Scientists have ascertained that the right testis is larger than the left. This is true for weights of the parenchyma and the tunic as well as for the total weight and volume of the testis. The difference is about a $10 \%$ reduction in weight on the left side [4]. Our results approved that the right testes had significantly larger length, height, volume and weight in comparison with the left. Due to the smaller size of the left testis, it produces fewer spermatozoa on average than the right $[2,4,5,12]$. 


\section{CONCLUSIONS}

The length, height, volume and weight of the right testis in 41-50-years-old men were significantly larger than those of the left testes. Only the width of the right and left testes differed statistically non-significantly.

\section{REFERENCES}

1. Bhat S., Sathyanarayanaprasad M., Giridhar A., Srinivasa Y., Paul F. (2016). Testicular Volume Measurement: Comparison of Prader's Orchidometry, Ultrasonography, and Actual Volume by Water Displacement. Journal of Integrative Nephrology and Andrology, 3, 3, 92-95.

https://doi.org/10.4103/2394-2916.187793

2. Boisen E. (1979). Testicular size and shape of $47, \mathrm{XYY}$ and $47, \mathrm{XXY}$ men in a double-blind, double-matched population survey. American Journal of Human Genetics, 31, 6, 697-703.

3. Innocent M.C., Asomugha L.A., Ukamaka M.N., Aronu M.E. (2016). Ultrasound measured testicular volume in Nigerian adults: Relationship of the three formulae with height, body weight, body-surface area, and body-mass index. International Journal of Advanced Medical and Health Research, 3, 2, 85-90. https://doi.org/10.4103/2349-4220.195940

4. Johnson L., Petty C.S., Neaves W.B. (1984). Influence of age on sperm production and testicular weights in men. Journal of Reproduction and Fertility, 70, 1, 211-218. https://doi.org/10.1530/jrf.0.0700211

5. Kristo A., Dani E. (2014). The Correlation between Ultrasound Testicular Volume and Conventional Semen Parameters in Albanian Subfertile Males. Macedonian Journal of Medical Sciences, 7, 3, 464-466.

https://doi.org/10.3889/oamjms.2014.081

6. Kuijper E.A.M., van Kooten J., Verbeke J.I.M.L., van Rooijen M., Lambalk C.B. (2008). Ultrasonographically measured testicular volumes in 0 - to 6-year-old boys. Human Reproduction, 23, 4, 792-796.

https://doi.org/10.1093/humrep/den021

7. Mbaeri T.U., Orakwe J.C., Nwofor A.M., Oranusi K.C., Mbonu O.O. (2013). Accuracy of Prader orchidometer in measuring testicular volume. Nigerian Journal of Clinical Practice, 16, 3, 348-351. https://doi.org/10.4103/1119-3077.113460

8. Mbaeri T.U., Orakwe J.C., Nwofor A.M.E., Oranusi C.K., Mbonu O.O. (2013). Ultrasound measurements of testicular volume: Comparing the three common formulas with the true testicular volume determined by water displacement. African Journal of Urology, 19, 2, 69-73. https://doi.org/10.1016/j.afju.2012.11.004 
9. Sakamoto H., Saito K., Oohta M., Inoue K., Ogawa Y., Yoshida H. (2007). Testicular Volume Measurement: Comparison of Ultrasonography, Orchidometry, and Water Displacement. Urology, 69, 1, 152-157. https://doi.org/10.1016/j.urology.2006.09.012

10. Sakamoto H., Ogawa Y., Yoshida H. (2008). Relationship between testicular volume and testicular function: comparison of the Prader orchidometric and ultrasonographic measurements in patients with infertility. Asian Journal of Andrology, 10, 2, 319-324. https://doi.org/10.1111/j.1745-7262.2008.00340.x

11. Sotos J.F., Tokar N.J. (2012). Testicular volumes revisited: A proposal for a simple clinical method that can closely match the volumes obtained by ultrasound and its clinical application. International Journal of Pediatric Endocrinology, 2012, 1, 17. https://doi.org/10.1186/1687-9856-2012-17

12. Tsili A.C., Ntorkou A., Giannakis D., Sofikitis N., Argyropoulou M.I. (2017). Normal testes asymmetry evaluated by apparent diffusion coefficient and magnetization transfer ratio. Acta Radiologica, 58, 7, 883-889.

https://doi.org/10.1177/0284185116674502

\section{Address for correspondence:}

Kristina Lasienè

Dept. of Histology and Embryology,

Faculty of Medicine, Medical Academy,

Lithuanian University of Health Sciences,

A. Mickevičiaus 9, LT-44307 Kaunas, Lithuania

E-mail: Kristina.Lasiene@lsmuni.lt 